\section{Treatment Disparities Faced by Undocumented Workers From Low- and Middle-Income Countries in the United States With Hematologic Malignancies}

\author{
Sara E. Nunnery, BA; Andrew E. Fintel, DO; W. Clay Jackson, MD; \\ Jason C. Chandler, MD; Michael O. Ugwueke, DHA, MPH; and \\ Mike G. Martin, MD
}

Acute and chronic leukemias are potentially curable with systemic chemotherapy and hematopoietic stem cell transplantation (HSCT), but they present a challenge within oncology due to the intense amount of supportive care required during treatment. Furthermore, the millions of undocumented immigrants currently living in the United States have extremely limited access to life-saving treatments if diagnosed with a catastrophic illness such as a hematologic malignancy. The inadequate access to cancer care in the United States faced by these immigrants is a growing issue that needs to be confronted by the medical community.

\section{Cancer Care for Immigrants in the United States}

Census data from 2011 suggest that more than 18 million foreign-born Hispanic immigrants living in the United States have emigrated from low- and middle-income countries (LMICs). Approximately 13 million immigrants are noncitizens of Mexican origin, and only $25 \%$ are lawfully present. ${ }^{1}$ Undocumented immigrants currently have limited access to health care in the United States. A study by Bustamante et al ${ }^{2}$ found that undocumented Mexican immigrants are significantly less likely to have had a physician visit in the previous year or have a regular source of health care compared with documented Mexican immigrants. Under the 2010 Patient Protection and Affordable Care Act, immigrants with documentation can purchase health insurance through exchanges, and low-income immigrants with documentation can be eligible for Medicaid after a 5-year waiting period. However, undocumented immigrants are still excluded from being able to purchase health insurance in the exchanges and from becoming eligible for Medicaid. ${ }^{3}$

Unless they can find physicians and facilities willing to provide pro bono treatment, undocumented immigrants diagnosed with catastrophic illnesses such as hematologic malignancies or other cancers have no options for receiving potentially life-saving treatments with chemotherapy, targeted therapies, and HSCTs. We have faced these treatment challenges with undocumented immigrants who presented to our institution with acute and chronic leukemias.

For example, a 21-year-old Hispanic man presented to our hospital with a WBC count of 103,000 cells $/ \mathrm{mcL}$ with $94 \%$ blasts. After he underwent urgent leukapheresis, a bone marrow biopsy was performed and a diagnosis of acute myeloid leukemia (AML) was made. He was started on induction chemotherapy with cytarabine, idarubicin, and cladribine $(7+3+5) .{ }^{4}$ The final bone marrow biopsy revealed high-risk AML with an MLL rearrangement $(45, \mathrm{X},-\mathrm{Y}, \mathrm{t}(10 ; 11)(\mathrm{p} 11.2 ; \mathrm{q} 23))$ and an isolated FLT3-ITD. His day 14 bone marrow biopsy showed a prominent blast population consistent with his initial biopsy, so he received salvage chemotherapy with cladribine, cytarabine, and mitoxantrone (CLAM)..$^{5}$ Repeat bone marrow biopsies on days 7 and 30 after CLAM showed a complete remission. He had originally come to the United States from Mexico on a work visa to pick apples, but his visa had expired before his presentation. Given his high-risk AML status, we felt an allogeneic stem cell transplant provided the best chance of cure. However, he would not be able to receive a transplant and the long-
Sara E. Nunnery, BA

Sara Nunnery is a student in the College of Medicine at The University of Tennessee Health Science Center in Memphis, Tennessee. She will graduate in May 2016 and will start her internal medicine residency at the University of California San Francisco in June 2016, where she plans to pursue a fellowship in hematology/oncology after completing residency.

Andrew E. Fintel, DO

Andrew E. Fintel, DO, is from the Department of Hematology/ Oncology, The University of Tennessee Health Science Center, Memphis, Tennessee.

W. Clay Jackson, MD

W. Clay Jackson, MD, is from the Department of Palliative Medicine, The University of Tennessee Health Science Center, Memphis, Tennessee. 
Nunnery et al

Jason C. Chandler, MD

Jason C. Chandler, MD, is from the Department of Hematology/ Oncology, The University of Tennessee Health Science Center, Memphis, Tennessee.

Michael O. Ugwueke, DHA, MPH

Michael Ugwueke, DHA, MPH, President and COO of Methodist Le Bonheur Healthcare System, is an accomplished healthcare executive with over 29 years' experience and a track record of developing partnership with physicians, associates, and community leaders to address health care needs in the community.

Mike G. Martin, MD

Mike G. Martin, MD, is from the Department of Hematology/ Oncology, The University of Tennessee Health Science Center, Memphis, Tennessee. term follow up care that it necessitates without charity financial support because of his undocumented immigration status and lack of insurance.

In another example, a 40-year-old Hispanic man presented to the hospital with generalized fatigue, weakness, and weight loss. He was found to have a WBC count of 205,000 cells/mcL, and the differential showed 1\% blasts, 2\% basophils, $14 \%$ myelocytes, and $1 \%$ promyelocytes. Chronic myeloid leukemia (CML) was confirmed with a bone marrow biopsy, which showed an isolated $\mathrm{t}(9 ; 22)$ without an increase in blasts. The patient was started on daily imatinib, and 4 weeks later his WBC count had improved to 5,900 cells $/ \mathrm{mcL}$. However, because he was also an illegal immigrant without insurance, he had difficulty obtaining the drug. He was unable to obtain imatinib for 1 month, potentially jeopardizing his long-term outcome. ${ }^{6}$ Imatinib for 1 year was eventually obtained through our hospital charity program, but the security of his long-term supply is unclear. No pharmaceutical company patient support program would accept him because of his illegal status.

These 2 patient cases from our institution illustrate the disparities in cancer care that undocumented immigrants currently face in hospitals and treatment centers in the United States.

\section{The Global Gap}

Unfortunately, despite the problems they face obtaining health care in the United States, for these immigrants returning to the countries from which they emigrated is usually not a better option. They are unlikely to have access to treatment in those countries due to increasing global cancer disparity. A 2009 report by the Economist Intelligence Unit estimated 12.9 million new cancer cases worldwide in 2009, with $39 \%$ in high-income countries and $61 \%$ in developing countries. ${ }^{7}$ In addition to increased incidence, these countries have much higher case fatality rates (ratio of cancer deaths to new cancer cases). Data from 2002 showed a case fatality rate in low-income countries of $74.5 \%$ compared with $46.3 \%$ in high-income countries. The Global Task Force on Expanded Access to Cancer Care and Control (GTF.CCC) reported that even though LMICs account for $80 \%$ of the global cancer burden, only $5 \%$ of global spending on cancer is directed to them. This is the so called " $5 / 80$ cancer disequilibrium."

Hematologic malignancies such as AML and CML are potentially curable with systemic chemotherapy; however, they represent a unique challenge within oncology due to the intense resources and expenses of the supportive care required during treatment. Even in the United States, outcomes vary based on access to experienced care. Giri et $\mathrm{al}^{9}$ found a significantly increased mortality rate (5.0\%) for adult patients with AML treated with chemotherapy in low-volume hospitals compared with highvolume hospitals (1.6\%) in the United States.

CML can be well controlled with systemic treatment, but the cost can be daunting. ${ }^{10}$ Oral tyrosine kinase inhibitors (TKIs) such as imatinib can control the disease long-term and are the initial treatment of choice. However, in the United States, a 90-day supply of imatinib costs more than $\$ 7,000$, creating financial barriers to obtaining these drugs for many patients. ${ }^{11}$

Many cytotoxic chemotherapies have become less expensive in recent years as generic forms become available in LMICs. ${ }^{8}$ National essential medicine lists (NEMLs), first created by the WHO in 1977, are used in many LMICs to prioritize medications needed for public procurement and reimbursement processes. ${ }^{12,13}$ Bazargani et $\mathrm{al}^{12}$ surveyed NEMLs in 76 LMICs and found that the average number of cytotoxic chemotherapies on NEMLs was 16 . However, more than $75 \%$ of NEMLs had no monoclonal antibodies or TKIs listed. This suggests that these 
newer therapies are still widely unavailable. For example, in June 2015, a group of 166 patients with cancer in El Salvador marched to the Legislative Assembly in protest because they were unable to obtain imatinib for 2 weeks when the hospital ran out of its supply, which must be donated by pharmaceutical companies. ${ }^{14}$

HSCT is the only treatment option that can offer a cure for many types of high-risk leukemia, but this option is extremely limited in LMICs. Because of the high cost of the procedure, required long-term follow-up care, and the need for a multidisciplinary health care team, very few centers in developing countries perform HSCTs. A 2010 report by Rodriguez-Romo et $\mathrm{a}^{15}$ is the first report that attempts to gather data on HSCTs in an LMIC-Mexico-where there is no qualified registry or database to track HSCTs and their outcomes. The authors surveyed the 7 pediatric centers in Mexico and found a total of 127 HSCTs were performed from 2007 to 2008. This total is well below that of, for example, a high-income country such as Spain. Similar data for adult HSCTs are lacking. For example, Mexico has no populationbased national cancer registry, so gathering epidemiologic data is a complex process that occurs through multiple sources. Consequently, any reported epidemiologic statistics and trends in Mexico that are available must be interpreted with caution. ${ }^{16}$

\section{Conclusions}

Fortunately for the patients described previously, our hospital was able to fund treatment through the $340 \mathrm{~B}$ Drug Pricing Program, which requires that drug manufacturers provide significant discounts on outpatient drugs to covered hospitals. ${ }^{17,18}$ Public and nonprofit hospitals are eligible to participate in the program if they serve a disproportionate percentage of uninsured or low-income patients or meet other specific criteria. ${ }^{19}$ The hospital can purchase a drug at the discounted price for a patient regardless of the patient's insurance status as long as the patient receives health care services from the covered hospital. ${ }^{17,19}$

However, immigrants from LMICs continue to face inadequate access to treatment both in their home countries and often in the United States. Critics of expanding global cancer care who live in high-income countries may be tempted to consider cancer disparities to be an issue of those LMICs, in the vein of "out of sight, out of mind." But these issues are in the United States and directly affect millions of immigrants each day. Continued epidemiologic research will help us to further elucidate discrepancies in cancer outcomes and to identify the changes and reforms needed to increase access to treatment for immigrants. These disparities at home and abroad should not be ignored and must be confronted by the global medical community.

\section{References}

1. Stepler R, Brown A. Stastitical Portrait of Hispanics in the United States, 1980-2013. 2015; Washington DC; Pew Research Center. Available at: http://www.pewhispanic.org/2015/05/12/statistical-portrait-of-hispanics-inthe-united-states-1980-2013/. Accessed March 15, 2016.

2. Bustamante VA, Fang H, Garza J, et al. Variations in healthcare access and utilization among Mexican immigrants: the role of documentation status. J Immigrant Minor Health 2012;14:146-155.

3. Bustamante VA, Laugesen M, Caban M, Rosenau P. United States-Mexico cross-border health insurance initiatives: Salud Migrante and Medicare in Mexico. Pan Am J Public Health 2012;31:74-80.

4. Wiedower $\mathrm{E}$, Jamy $\mathrm{OH}$, Martin MG. Induction of acute myeloid leukemia (AML) with idarubicin, cytarabine, and cladribine (ICC) [abstract]. J Clin Oncol 2015;33(Suppl):Abstract 18048.

5. Martin MG, Welch JS, Augustin K, et al. Cladribine in the treatment of acute myeloid leukemia: a singleinstitution experience. Clin Lymphoma Myeloma 2009;9:298-301.

6. Mathisen MS, Kantarjian HM, Cortes J, Jabbour EJ. Practical issues surrounding the explosion of tyrosine kinase inhibitors for the management of chronic myeloid leukemia. Blood Rev 2014;28:179-187. 
Nunnery et al

7. Beaulieu NB, Bloom R, Stein R. Breakaway: the global burden of cancer-challenges and opportunities: a report from the Economist Intelligence Unit. Available at: http://graphics.eiu.com/upload/eb/EIU_LIVESTRONG_ Global_Cancer_Burden.pdf. Accessed March 16, 2016.

8. Knaul FM, Frenk J, Shulman L, for the Global Task Force on Expanded Access to Cancer Care and Control in Developing Countries. Closing the Cancer Divide: A Blueprint to Expand Access in Low and Middle Income Countries. Available at: http://gtfccc.harvard.edu/fs/docs/icb.topic1063570.files/ccd_report_111027.pdf. Accessed March 16, 2016.

9. Giri S, Pathak R, Aryal MR, et al. Impact of hospital volume on outcomes of patients undergoing chemotherapy for acute myeloid leukemia: a matched cohort study. Blood 2015;125:3359-3360.

10. Farmer P, Frenk J, Knaul FM, et al. Expansion of cancer care and control in countries of low and middle income: a call to action. Lancet 2010;376:1186-1193.

11. Gleevec. RedBook Web site. Available at: www.redbook.com/redbook/online/. Accessed June 62015.

12. Bazargani YT, de Boer A, Schellens JH, et al. Selection of oncology medicines in low- and middle-income countries. Ann Oncol 2014;25:270-276.

13. World Health Organization. WHO Model List of Essential Medicines. Available at http://www.who.int/medicines/ publications/essentialmedicines/en/. Accessed June 6, 2015.

14. Caceres Y. Pacientes del Rosales con cancer temen por sus vidas. Available at: http://www.elsalvador.com/mwedh/ nota_completa.asp?!dCat=47673\&idArt=9731964. Accessed June 12, 2015.

15. Rodriguez-Romo L, Gonzalez-Llano O, Mancias-Guerra C, et al. Pediatric hematopoietic SCT in Mexico: recent activity and main problems. Bone Marrow Transplant 2011;46:607-609.

16. Forouzanfar MH, Foreman KJ, Delossantos AM, et al. Breast and cervical cancer in 187 countries between 1980 and 2010: a systematic analysis. Lancet 2011;378:1461-1484.

17. Policy Statement on the 340B Drug Pricing Program by the American Society of Clinical Oncology. J Oncol Practice 2014;10:259-263

18. Office of Pharmacy Affairs. 340B Drug Pricing Program. Avaialable at: http://hrsa.gov/opa/. Accessed March 16 , 2016.

19. Warren A, Shankar A. Oncology transactions and the 340B Drug Pricing Program. J Oncol Practice 2013;9:89-91. 